\title{
Acoustic communication during reproduction in the basal gobioid Amur sleeper and the putative sound production mechanism
}

\author{
S. Horvatić ${ }^{1}$, S. Malavasi ${ }^{2}$, E. Parmentier ${ }^{3}$, Z. Marčić ${ }^{1}$, I. Buj ${ }^{1}$, P. Mustafić ${ }^{1}$, M. Ćaleta ${ }^{4}$, M. Smederevac-Lalić ${ }^{5}$, \\ S. Skorić ${ }^{5} \&$ D. Zanella ${ }^{1}$ \\ ${ }^{1}$ Department of Zoology, Faculty of Science, University of Zagreb, Zagreb, Croatia \\ ${ }^{2}$ Department Environmental Sciences, Informatics and Statistics, Ca' Foscari University of Venice, Venezia Mestre, Italy \\ ${ }^{3}$ Laboratoire de Morphologie Fonctionnelle et Evolutive, AFFISH-RC, Institut de Chimie - B6C, Université de Liège, Liège, Belgium \\ ${ }^{4}$ Faculty of Teacher Education, University of Zagreb, Zagreb, Croatia \\ ${ }^{5}$ Institute for Multidisciplinary Research, University of Belgrade, Belgrade, Serbia
}

\section{Keywords}

Perccottus glenii; vocal fish; tonal sounds; sound production; acoustic behaviour; levator pectoralis muscle; acoustic communication; gobioids.

\section{Correspondence}

Davor Zanella, Department of Zoology, Faculty of Science, University of Zagreb, Rooseveltov trg 6, 10000, Zagreb, Croatia. Tel: +385(0)1 6189709

Email: davor.zanella@biol.pmf.hr

Editor: Jean-Nicolas Volff

Received 3 January 2019; revised 25 June 2019; accepted 1 July 2019

doi:10.1111/jzo.12719

\begin{abstract}
Gobioids (Gobiiformes: Gobioidei) are a large group of vocal fishes with four sound types documented during aggressive or reproductive interactions in 23 species. Most attention has been dedicated to sound production in Gobiidae and Gobionellidae, while acoustic communications in other phylogenetically distant gobioid groups have been neglected. Odontobutidae, a basal family within the gobioids, is a poorly studied fish assemblage, with sounds documented in only a single species. The goal of this study was to record and describe the acoustic signals produced by Perccottus glenii (Odontobutidae) under laboratory conditions, with particular focus on the reproductive phase (courtship and pre-spawning), and to provide insight into the anatomical basis of the sound emission mechanism. We recorded two acoustically different call types, thumps and tonal sounds. Thumps were low-frequency sounds $(\sim 95 \mathrm{~Hz})$ with an irregular waveform, produced by males during both the courtship and pre-spawning phases. Thumps were frequently organized in long trains, a thump burst, composed from approximately five thumps and lasting over $10 \mathrm{~s}$. Tonal sounds were short vocalizations $(\sim 90 \mathrm{~ms})$ produced only during courtship interactions, characterized by a sinusoidal oscillogram and a single frequency peak $(\sim 120 \mathrm{~Hz})$. Additionally, anatomical examination focusing on the pectoral girdle identified the muscles that could be responsible for sound emission. The levator pectoralis muscle, originating on the neurocranium and attaching to the cleithral bone, is separated into three bundles: a pars lateralis superficialis, a pars lateralis profundus and a pars medialis. These results expand the knowledge about gobioid vocal behaviour and underline the importance of acoustic communication within this group of fish. Odontobutidae is a sister group to rest of the gobioids, and therefore, our results have significant impact for future comparative studies dealing with sound production.
\end{abstract}

\section{Introduction}

Although numerous fishes can produce different sounds, their production for social communication is documented in a restricted number of species from around 110 families (Parmentier \& Fine, 2016). Gobioid fishes (phylogeny according to Thacker, 2009) form one of the most investigated Teleost groups in terms of vocal repertoire. Within this group, acoustic communication has been documented in 23 species (Horvatić et al., 2015; Zeyl et al., 2016). In general, gobioid sound emission occurs during agonistic and reproductive contexts. Acoustically, the reproductive sequence can be further subdivided into the courtship, pre-spawning and spawning phases (Lugli et al., 1997; Myrberg \& Lugli, 2006; Amorim \& Neves, 2007; Malavasi, Valerio \& Torricelli, 2009; Blom et al., 2016; Zeyl et al., 2016). Courtship behaviour usually commences from the moment the female enters the male territory, while the pre-spawning phase is characterized with the ripe female entering the male's nest. When the female inverts in the nest to release eggs onto the ceiling, spawning has started.

Four major sound types can be recognized in gobioids: pulsed sounds consisting of pulse trains repeated at a slow rate, tonal sounds characterized by faster pulse repetition rates 
and a sinusoidal-like waveform, and complex sounds that are a combination of the two (Lugli et al., 1997; Zeyl et al., 2016). Lastly, thump sounds are short low-frequency pulsed signals with sound energy under $1 \mathrm{kHz}$ (Amorim \& Neves, 2007; Malavasi, Collatuzzo \& Torricelli, 2008; Zeyl et al., 2016). Briefly, in the most investigated species, pulse trains dominate during both agonistic and reproductive (pre-spawning) interactions, while thumps and tonal sounds are involved in courtship activities in many gobioids (Ladich \& Kratochvil, 1989; Lugli et al., 1996; Lindström \& Lugli, 2000; Amorim \& Neves, 2007, 2008; Malavasi et al., 2008, 2009; Horvatić et al., 2015; Zeyl et al., 2016). Complex sounds, reported in only three gobioids to date, were recorded during aggressive circumstances (Gobius cruentatus and Periophthalmodon septemradiatus) or as a part of spawning acoustic repertoire in Padogobius bonelli (Lugli et al., 1995, 1997; Sebastianutto et al., 2008; Polgar et al., 2011; Zeyl et al., 2016).

Recently, molecular studies of the relationships between the gobioids strongly support that Odontobutidae is a sister group of all other lineages (Thacker, 2009; Agorreta et al., 2013). This group contains 22 species, with acoustic communication studied in just one species: Odontobutis obscura (Takemura, 1984). The acoustic feature of its recorded calls resembles the pulsatile sounds previously documented in many other gobies (see Zeyl et al., 2016). These results support the claim that sound production based on pulsed repertoires could be a synapomorphic trait within the gobioids (Malavasi et al., 2008; Zeyl et al., 2016). However, additional acoustic research is required to understand the ancestral state of sound communication in gobioid fishes.

The diversity of sonic mechanisms in fishes is so great that it has not been possible to group them in appropriate categories (Ladich \& Fine, 2006). In gobioids, different mechanisms have been proposed; however, these hypotheses should be considered with caution as they have rarely been tested, and deeper multidisciplinary investigations are needed to fully understand sound production in the gobioids. Parmentier et al. (2013, 2017a) experimentally tested the hypothesis of contraction of the pectoral girdle muscles in two European gobies, Gobius paganellus and Pomatoschistus pictus (Gobiidae and Gobionellidae, respectively). Multidisciplinary investigation (sound analysis, electromyography and electron microscopy), together with morphological and high-speed videos, has suggested that drumming sounds might be generated by the periodic contraction of the levator pectoralis muscle (Parmentier et al., 2013, 2017a). These findings proposed that the pectoral girdle mechanism could be common to the gobies and may have possibly evolved in other gobioid groups as an exaptation (Parmentier, Diogo \& Fine, 2017b), likely from locomotory movements.

Perccottus glenii Dybowski, 1877 is a freshwater gobioid fish, widespread in the lentic waters, ponds and marshes of Europe and Central Asia (Kottelat \& Freyhof, 2007; Freyhof, 2011). It belongs to the family Odontobutidae, an early branching lineage of the Gobiiformes, native to East Asia (Kottelat \& Freyhof, 2007; Thacker, 2009), and as such offers a great opportunity to expand the knowledge on the vocal repertoire in Odontobutidae and to better clarify the ancestral acoustic structure within the gobioid fishes. The spawning habits of $P$. glenii are similar to the general goby pattern, and during reproduction, which starts in May or July, P. glenii males occupy and defend nests that are used as spawning sites and exhibit territorial behaviour (Miller, 1986; Kottelat \& Freyhof, 2007).

The aim of the present study was to assess the patterns of acoustic communication in $P$. glenii during courtship while also providing insight into the anatomical basis of the sound emission mechanism. More specifically, the goals were to: (1) document sound production during reproduction in the male $P$. glenii and quantitatively describe the sound structure; (2) explore the association between reproductive behaviours and sound production; and (3) investigate the morphological components of the pectoral girdle and associated muscles possibly related to sound production in the odontobutid P. glenii.

\section{Materials and methods}

The study was carried out from April until the end of June 2018, which corresponds with the breeding season of $P$. glenii. Fish were caught in October 2017 from a well-vegetated tributary to the main Danube River channel, near Veliko Gradište (Serbia). Individuals (25 individuals; 10 males and 15 females) were collected using electrofishing and transported to the laboratory where they were sexed according to urogenital papillae (conical in males, wider and fimbriose in females; Miller, 2003) and separated by sex into two stock glass tanks (each 120 L). Six males exhibiting pronounced breeding behaviour with obvious dimorphic traits (swollen nape and dark coloration) were used as residents in acoustic tests and placed individually in 90-L glass tanks. Each tank was supplied with a tile shelter to serve as a nest, aerators to ensure optimal oxygen levels and a gravel or fine sand substrate layer on the bottom. To avoid sound disturbance and minimize the surrounding noise during audio recordings, each tank was placed on foam-rubber shims. Photoperiod and water temperature followed natural environmental reign, and in situations when water temperature dropped below $15^{\circ} \mathrm{C}$, water heater (ATMAN brand; AT 1008 type; temp. range: $20-34^{\circ} \mathrm{C}$ ) was used to maintain optimal water temperatures for reproduction (Miller, 2003). Inside each tank, water temperature (range: 15.7-20.8 ${ }^{\circ} \mathrm{C}$ ) was monitored with the thermometer (AQUATERRA, Garešnica, Croatia).

\section{Experimental procedure}

Sounds were recorded from six males (size range: 84-96 mm $L_{\mathrm{S}}$ ), during the reproductive interactions (courtship and prespawning phases). Experiments were set up according to the protocol provided by Horvatić et al. (2015) to record reproductive (male-female) or aggressive interactions (male-male). We used an acoustic intruder test, during which the fish was left in the observational tank for acclimatization (10-15 days) to establish territoriality. An intruder (i.e. a female showing an enlarged belly and nuptial coloration, or aggressive male) was selected from the stock tank. The intruder fish (size range: 73$89 \mathrm{~mm} L_{\mathrm{S}}$ ) was placed in metal cage in front of the nest in 
the observational tank to elicit a behavioural or acoustic response from the resident male. Each session lasted $c$. 30 min. All pump devices, aerators and lights were switched off $10 \mathrm{~min}$ prior to recordings to minimize ambient noise.

\section{Sound collection}

Sound production was recorded at various times during the day with an omnidirectional H2A-XLR hydrophone (Aquarian Audio \& Scientific, Anacortes, WA, USA; sensitivity: $-180 \mathrm{~dB}$ re: $1 \mathrm{~V}^{-1} \mathrm{~Pa}$; frequency range $\pm 4 \mathrm{~dB}$ from 0.01 to $100 \mathrm{kHz}$ ) positioned less than $10 \mathrm{~cm}$ from the nest entrance according to Akamatsu et al. (2002). The hydrophone was connected to an IRIG PRE preamplifier (Aquarian Audio \& Scientific), and sounds were recorded using a ZOOM H4n portable digital audio recorder (wav 16/44.1 k mono; ZOOM, Tokyo, Japan), stored on the recorder memory card and monitored on headphones.

\section{Behavioural recording}

The courtship and pre-spawning phases of reproductive behaviour were video-recorded and analysed. Courtship behaviour began when the females entered into the male territory, while the pre-spawning phase was observed when the ripe female entered the male's nest. No sounds were produced during actual spawning. Video recordings of acoustic behaviour were performed using a camcorder (Canon Legria FS200, 2000× digital zoom, Tokyo, Japan) positioned c. $30 \mathrm{~cm}$ from the front of the experimental glass tanks. Audio recordings, as described above, were conducted simultaneously, enabling sounds to be associated with specific behaviours. Male behaviours and the associated sound emissions were observed during 17 recording sessions (2.8 per male) and analysed using Windows Movie Maker (size: 1004 bytes; Microsoft, Redmond, WA, USA). Behavioural categories expressed by the males were classified and scored according to our observations and the existing behavioural literature for gobioids (Takemura, 1984; Amorim \& Neves, 2007; Malavasi et al., 2009, 2012).

\section{Signal processing and sound analysis}

Analog sounds were digitalized at 4000 sampling rate (128 accuracy, 16 bit resolution) and high-pass filtered $(0.06 \mathrm{kHz})$ to eliminate background noise. Additionally, $+10 \mathrm{~dB}$ amplification was applied for better auditory and visual inspection of the audio tracks. Digitalized sounds were analysed using Avisoft-SASLab Pro 5.2 Software (512-point fast Fourier transform FFT, Hamming window; Avisoft Bioacoustics, Berlin, Germany). Only sounds with a good signal to noise ratio (SNR) were analysed. Temporal features were measured from the oscillogram, while frequency variables were obtained from the logarithmic power spectra (Hamming window, 512-points FFT, resolution $7 \mathrm{~Hz}$ ). More rarely, thumps were produced in sequences of several sounds, that is thump bursts, for which the sound parameters were also calculated. Visual inspection in the software allowed us to separate two different thump bursts according to a time interval longer than 2-s, which separated the last thump in one and the first thump in an additional burst. All thumps in the sequence with an interval shorter than 2 -s were considered one thump burst. The following acoustic properties were measured for thumps and thump bursts, respectively: (1) thump rate (number of thumps emitted in $1 \mathrm{~min}$; sound $\mathrm{min}^{-1}$ ); (2) thump duration (total length of the call, measured in milliseconds); (3) number of cycles; (4) peak frequency (obtained from the power spectrum function); (5) burst duration (total length of the thump burst, measured in seconds); (6) number of thumps in the burst; and (7) thump interval (time interval within the burst measured from the end of one thump to the start of the following one, measured in seconds). For tonal sounds, we measured the following: (1) sound rate (tonal sounds emitted in $1 \mathrm{~min}$; sound $\mathrm{min}^{-1}$ ); (2) duration (ms); (3) number of cycles; (4) cycle repetition rate (Hz); (5) frequency modulation (after the sound has been divided into three sections, frequency modulation was calculated as the difference between the final and initial cycle repetition rate and expressed in $\mathrm{Hz}$ ); and (6) peak frequency $(\mathrm{Hz})$.

\section{Statistical analysis}

The mean, standard deviation $(x \pm \mathrm{SD})$ and range for each acoustic variable emitted by individual fish were calculated. Sound features were examined using from 10 to 20 thumps, 10 thump bursts and 5 to 10 tonal sounds per individual, when possible. To investigate the behavioural context of sound production, two analyses were performed independently on the same dataset. The first was the chi-square test (at 5\% level of significance) used to study the association of sound production with particular behavioural displays, in both thumps and tonal sounds. Males courted females by displaying various behavioural displays: behaviours expressed by the males were quantified as the frequency of events, or the number of observed behavioural acts occurring in a given time $\left(n \min ^{-1}\right)$. Six behavioural categories were identified from the videos and analysed: leading, chase, nest display, frontal display, upsidedown and pre-spawning. Sounds from vocal individuals were pooled, and the number of times each behavioural category was performed with or without sound emissions was counted. Adjusted residuals from the chi-square test were then used to assess which behavioural categories were positively or negatively associated with the emission of sounds; that is, residuals indicated whether the frequency of the cell was respectively overrepresented or underrepresented in the sample compared to the expected frequency (Sebastianutto et al., 2008). The second analyses involved dividing the reproductive sequence into two phases (courtship and pre-spawning), and the number of sounds recorded per phase was noted, separately for each male. As previously mentioned, courtship and pre-spawning phases were recognized according to female absence or presence in the nest, respectively. For the comparison between the frequency of calls produced by each male during the courtship or pre-spawning phase, the $t$-test was applied for dependent samples (5\% level of significance) after logarithmic transformation of data. In addition, individual mean values of sound parameters were tested for correlation using the Pearson 
correlation to investigate their mutual relationships and relationship with physical characteristics (size and water temperature). Data were analysed with statistica 13 (Statsoft Inc., Tulsa, OK, USA).

\section{Morphology}

Eight males (six vocal and two randomly selected from stock aquaria, size range: $84-96 \mathrm{~mm} L_{\mathrm{S}}$ ) were removed from tanks using hand nets. All fish were measured, euthanized with an
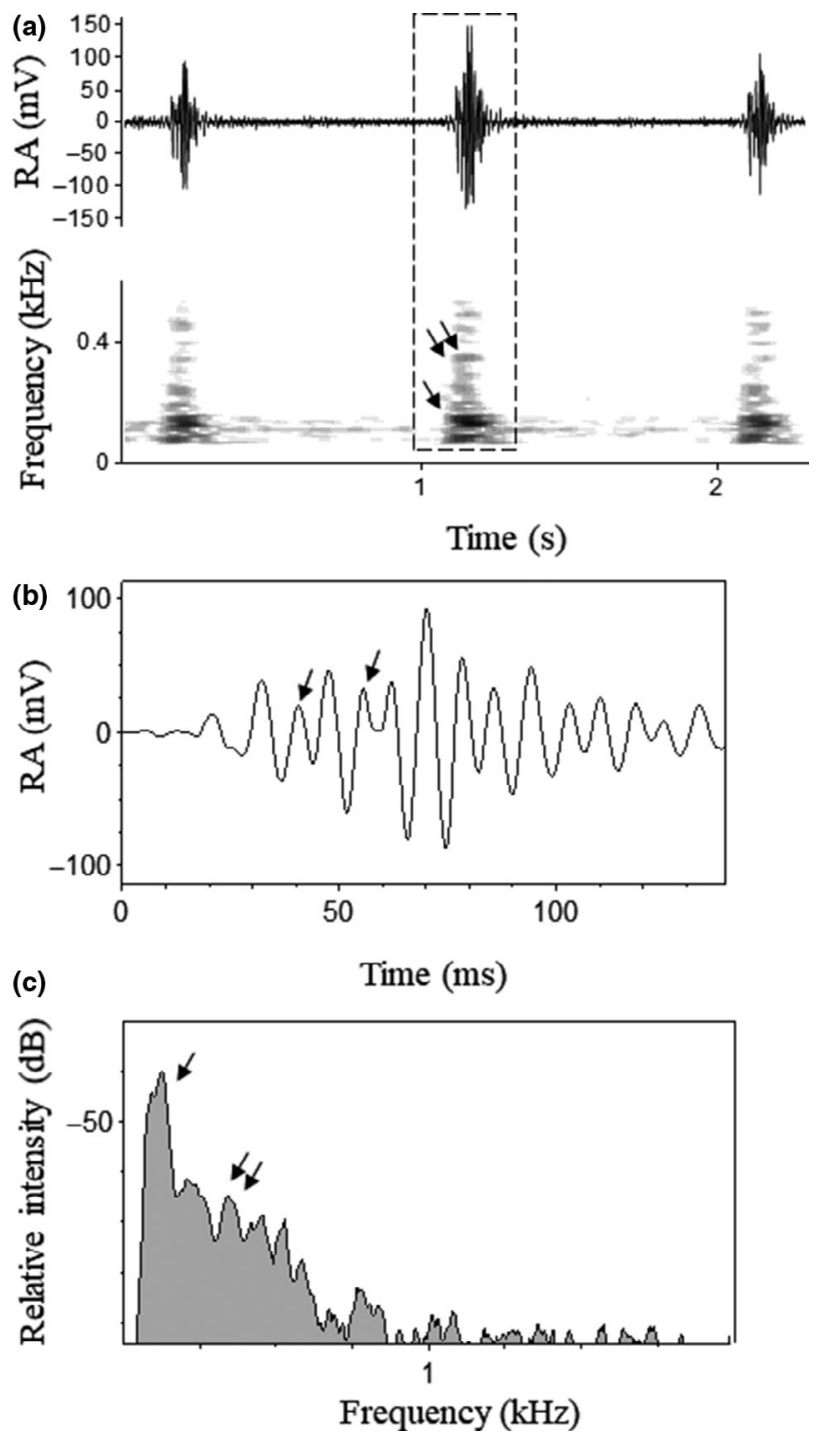

Figure 1 a) Oscillogram and spectrogram of the thump burst, b) enlarged oscillogram of an individual thump and c) power spectrum of the isolated thump produced during reproductive interactions of Perccottus glenii. On the spectrogram, the marked area represents an energy band (reaching up to $500 \mathrm{~Hz}$ ) with the arrows on the power spectrum indicating two frequency peaks (at 120 and $340 \mathrm{~Hz}$ ). Marked lines on the lower oscillogram represent sound duration, i.e. the onset and the end of one thump. On the oscillogram, arrows indicate extra-peaks. RA - relative amplitude. overdose of MS-222 (tricaine methane sulphonate; Pharmaq, Overhalla, Norway), and stored for 1 week in $7 \%$ formaldehyde fixative solution and then transferred to $70 \%$ ethanol. Dissections of specimens were performed at the University of Liège (Belgium). Fish were dissected and examined with a Wild M10 binocular microscope (Leica Camera, Leica, Wetzlar, Germany) equipped with a camera lucida. Dissections concern mainly muscles in relation to the pectoral girdle because of previous work implicating the pectoral fin motion in sound production. The nomenclature used to designate parts of the musculature is based on previous studies (Winterbottom, 1974; Adriaens, Decleyre \& Verraes, 1993).

\section{Results}

\section{Acoustic properties of reproductive calls}

Sound production was documented in six $P$. glenii males during reproductive interactions (courtship and pre-spawning). Males were acoustically active in the presence of females, mostly when they approached the nest entrance. A total of 734 sounds were documented, and 171 were analysed (mean $\pm \mathrm{SD}=15.3 \pm 6.8$ thumps per male; $8.6 \pm 3.2$ thump bursts per male; and $9.0 \pm 1.0$ tonal sounds per male). Thump sounds and thump bursts (long trains of thumps) were produced by all males though tonal sounds were produced by three males only. During male-male aggressive interactions, all males were mute and no sounds were documented.

Thumps are low-frequency sounds $(\sim 100 \mathrm{~Hz})$ composed of irregularly repeated sound cycles of a relatively short duration ( $\sim 95$ ms; Fig. 1a). On the waveform, cycles varied in amplitude but the highest peak was the one in the first two-thirds of the sound. The first individual cycle had one peak, while the following cycles exhibited smaller extra-peaks, which again disappeared as the sound ceased (Fig. 1b). On the power spectrum, fundamental frequency was always the dominant frequency representing the peak with greatest energy, but sometimes, additional harmonics were observed. Call energy was decreased by $c$. $-30 \mathrm{~dB}$ (relative intensity) by $600 \mathrm{~Hz}$ and did not exceed $1 \mathrm{kHz}$ (Fig. 1c, Table 1). During reproductive interactions, males produced a mean of 9 thumps $\min ^{-1}$, increasing vocal activity up to 19 thumps $\min ^{-1}$ when the female approached the nest. Thumps were organized in long trains, that is sound bursts, in which thumps were spaced with a time interval of $c .1 .2 \mathrm{~s}$ when the female hesitated on the nest entrance or was inspecting the cavity (Fig. 1a, Table 1). Bursts were composed from 2 to 11 thumps and in some cases lasted more than $10 \mathrm{~s}$. Within the burst, thumps had the same structure and temporal organization as when produced as individual thumps; that is, they were short duration and low-frequency signals. The number of thumps within the burst was positively correlated with burst duration (Pearson $r^{2}=0.97, P<0.05$; Fig. 2). Positive and significant correlations were detected between water temperature and three thump burst parameters: number of cycles (Pearson $r=0.44, N=6, P<$ 0.05 ), cycle repetition rate (Pearson $r=0.30, N=6, P<0.05$ ) and peak frequency (Pearson $r=0.40, N=6, P<0.05$ ).

Perccottus glenii males also produced short tonal sounds. These were produced inside the nest or from its opening 
during courtship in the presence of the ripe female. These sounds were never produced when the female entered the nest during the pre-spawning phase. Tonal sounds were short sinusoidal vocalizations ( $\sim 90 \mathrm{~ms}$ ) composed of about 10 sound cycles, whose repetition rate ranged from 91 to $125 \mathrm{~Hz}$ (Fig. 3a,b). Peak frequency was low $(\sim 120 \mathrm{~Hz})$ and appeared as a narrow peak on the spectrogram, strongly overlapping with the values of the cycle repetition rate (Fig. 3c, Table 2). In all cases, peak frequency was the fundamental frequency. Energy ranged up to $300 \mathrm{~Hz}$ and did not exceed $500 \mathrm{~Hz}$. Frequency modulation was slightly upward, with values averaging around $3 \mathrm{~Hz}$. Sound rate was lower when the female was further from the nest, but increased as the female approached the nest entrance. In these situations, tonal sounds were organized in series, averaging six repeated sounds per minute (Fig. 3a, Table 2). Sound variables, such as sound rate and frequency modulation, correlated positively with water temperature (Pearson $r=0.80$ and $r=0.40$, respectively; both $N=3$, $P<0.05)$.

\section{Behavioural context of sound production}

During reproductive interactions, the male courted the female by performing a series of breeding displays separated in the six behavioural categories (Fig. 4), while swimming or while supported on the substrate by the pelvic fins. Body and head movements observed during the sound emission in vocal fishes were similar for both thump and tonal calls, without any obvious differences in terms of motions. During sound production, fish exhibited pectoral fin abduction, rapid thrust of the throat region, and fin erection and body undulation. There was no sound production during actual spawning (egg laying).

During the 17 recording sessions (2.8 per male), 304 behavioural acts were identified and separated into the six behavioural categories. In total, 85 behaviours (42\%) were associated with sound production. Generally, the most
Table 1 Sound parameters of recorded thumps and thump burst during reproductive interactions in six Perccottus glenii males

\begin{tabular}{lrrl}
\hline Sound parameters & Mean & SD & Range \\
\hline Thumps & & & \\
$\quad$ Thump rate (sounds min $^{-1}$ ) & 9.3 & 3.2 & $2-18.5$ \\
Duration (ms) & 95.5 & 7.3 & $64.0-148.0$ \\
$\quad$ Number of cycles & 8.7 & 0.9 & $6.3-13.1$ \\
$\quad$ Peak frequency $(\mathrm{Hz})$ & 97.9 & 4.4 & $74-121.1$ \\
Thump bursts & & & \\
$\quad$ Thump duration (ms) & 99.9 & 32.8 & $66.1-157.0$ \\
Thump number of cycles & 7.6 & 1.1 & $5.5-9.2$ \\
$\quad$ Thump peak frequency $(\mathrm{Hz})$ & 95.0 & 9.2 & $81.6-108.9$ \\
$\quad$ Burst duration (s) & 4.4 & 3.8 & $1.3-13.2$ \\
$\quad$ Number of thumps & 4.4 & 3.1 & $2-11.5$ \\
$\quad$ Thump interval (s) & 1.2 & 0.2 & $0.9-1.5$ \\
\hline
\end{tabular}

frequently observed behavioural categories (irrespective of sound type) were as follows: Nest display $(33 \%, n=99)$, Frontal display $(22 \%, n=68)$ and Leading $(21 \%, n=66)$. Tonal sounds were most commonly recorded during Frontal display $(75 \%, n=28)$, while $62 \%$ of documented categories were associated with sound production (23 of 37 behaviours; Fig. 5). Thumps were most frequently observed during Nest display $(35 \%, n=94)$ and Leading $(24 \%, n=65)$. Only $23 \%$ of behavioural categories were associated with thumps (62 of 267 behaviours; Fig. 5).

Sound production differed in its association with the behavioural categories. The emission of thumps was positively associated with Frontal display and Pre-spawning $\left(\chi^{2}(6)=804.2, P<0.001\right)$. A positive association was also found between tonal sounds and Frontal display $\left(\chi^{2}(6)=62.3\right.$, $P<0.001)$, while fewer tonal sounds than statistically expected were observed in other categories $\left(\chi^{2}(6)=62.3, P<0.001\right)$. In addition, there was a significant difference between courtship and pre-spawning in the frequency of recorded sounds only in

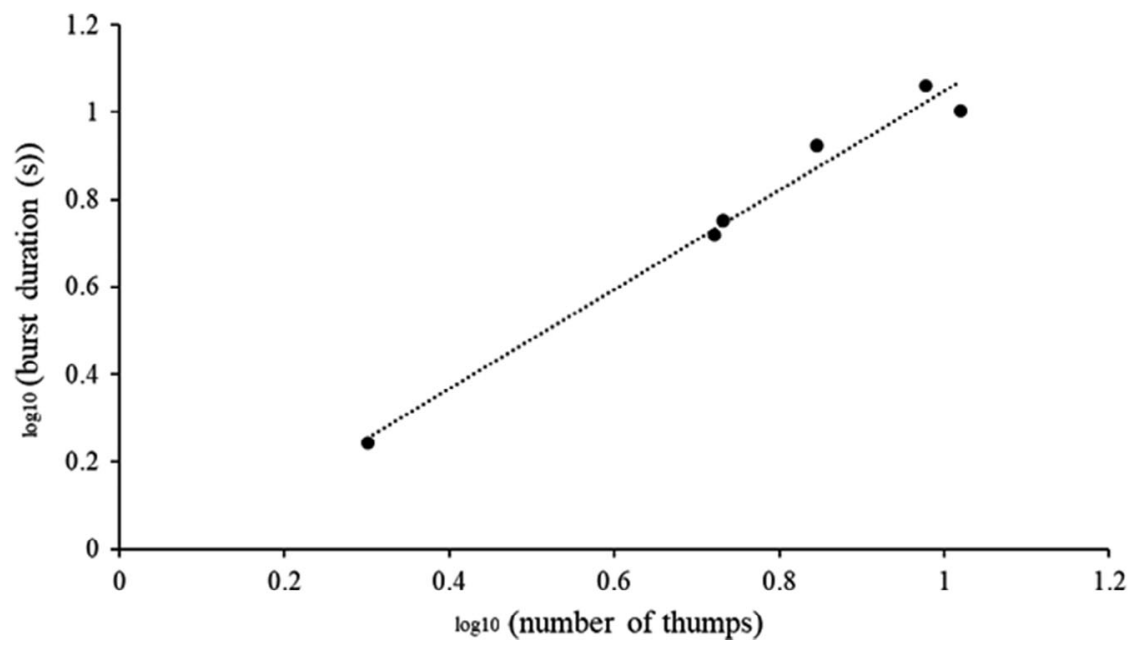

Figure 2 Relationship between burst duration and the number of thumps in Perccottus glenii. The curve was fitted by: $y=1.1354 x-0.0861\left(r_{2}\right.$ $=0.97, \mathrm{P}<0.05$ ). 


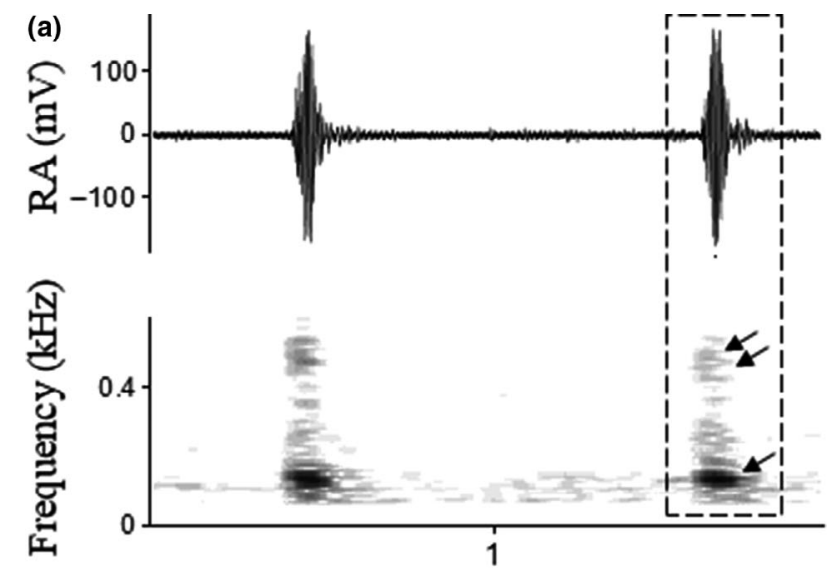

Time (s)
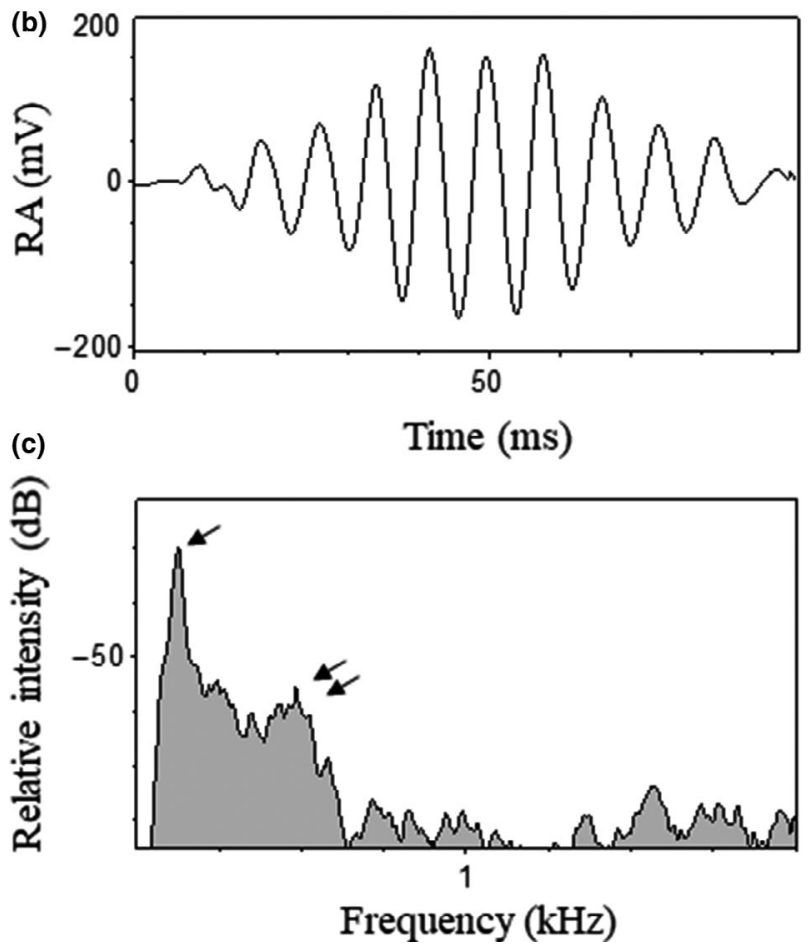

Figure 3 a) Oscillogram and spectrogram of the sinusoidal tonal sounds, b) enlarged oscillogram of an individual tonal sound and c) power spectrum of the isolated tonal sound produced during reproductive interactions (courtship) of Perccottus glenii. On the spectrogram and power spectrum, the marked area represents the energy band (reaching up to $500 \mathrm{~Hz}$ ) with the arrows on the power spectrum indicating important frequency peaks (at 120 and $470 \mathrm{~Hz}$ ). Marked lines on the lower oscillogram represent sound duration, i.e. the onset and the end of one tonal sound. RA relative amplitude.

the case of the tonal calls, where sounds were produced more frequently during courtship than pre-spawning (mean $\pm \mathrm{SD}$; courtship $=9 \pm 1$ vs. pre-spawning $=1 \pm 0$, dependent $t$ test $=34.02$, d.f. $=2, P<0.001)$. For thumps, there was no significant difference between the courtship or pre-spawning phases and the frequency of produced calls (courtship $=63.5 \pm 47.9 \quad$ vs. $\quad$ pre-spawning $=54.6 \pm 73.0$, dependent $t$-test $=1.29$, d.f. $=5, P>0.05$ ).

\section{Anatomical findings}

In previous studies on the sound-producing mechanisms in Gobiidae and Gobionellidae (Parmentier et al., 2013, 2017a), anatomical studies mainly concerned the pectoral girdles and associated muscles, that is levator pectoralis muscles, whose contractions were thought to be responsible for pectoral girdle motion during sound emission. In $P$. glenii, the pectoral girdle is articulated on the skull by the posttemporal bone. It consists of a basal plate with two processes that form a fork, preventing forward displacement of the posttemporal bone (Fig. 6). The dorsal process articulates dorsally on the skull at the level of the epiotic. The ventral process is situated beneath the dorsal process and extends rostrally into a ligament attached to the intercalar bone. The supracleithrum connects the posttemporal to the cleithral bone. It is anteriorly covered by the posttemporal, but is caudally lateral to the dorsal process of the cleithrum. Baudelot's ligament inserts on the medial face of the supracleithrum, bypasses caudally the anterior process of the cleithrum and inserts laterally on the basioccipital. Muscles described as sound-producing muscles were found in this part of the body.

The levator pectoralis muscle is easily distinguishable and is separated into three bundles: a pars lateralis superficialis, a pars lateralis profundus and a pars medialis (Fig. 6). The musculus levator pectoralis pars lateralis superficialis originates from the dorsal caudal part of the pterotic bone of the neurocranium and inserts on the medial face of the posttemporal, at the level of the basal plate. Some fibres also insert on the ventral process of the posttemporal. The musculus levator pectoralis pars lateralis profundus originates on the caudal margin of the pterotic bone, rides ventrally along the ventral process of the posttemporal and inserts on the rostral margin of the cleithral bone. The musculus levator pectoralis pars medialis originates more medially, on the exoccipital bone, and is attached to the rostral side of the cleithral bone. On the cleithral bone, the insertion of the pars medialis is dorsal to pars lateralis.

\section{Discussion}

The present study provides a qualitative and quantitative assessment of the acoustic behaviour in the basal gobioid $P$. glenii during reproduction and some insights into the putative sound emission mechanism. Perccottus glenii males produced two different sound types, thumps and tonal sounds, during courtship and pre-spawning interactions. We did not record sounds during male intrasexual aggressive interactions, what is interesting result considering high territoriality and breeding competition observed in $P$. glenii males and gobioids in general (Takemura, 1984; Lugli et al., 1997; Amorim \& Neves, 2008). Thumps were the most frequent sound type and were produced during both courtship and pre-spawning, while 
1. Leading

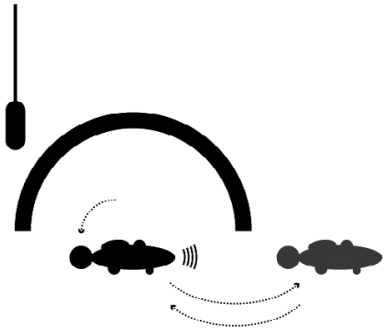

3. Nest display

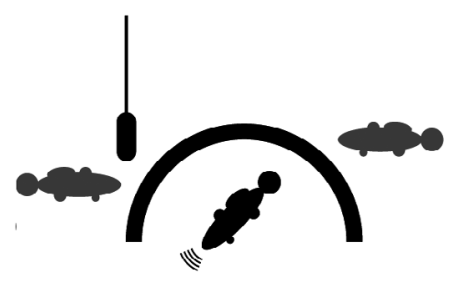

5. Upside - Down

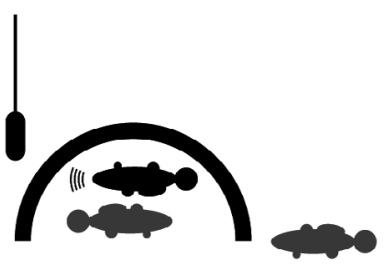

2. Chase

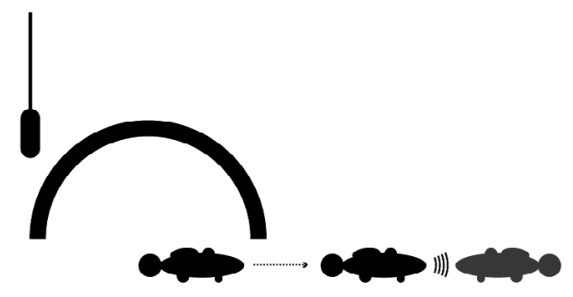

4. Frontal display

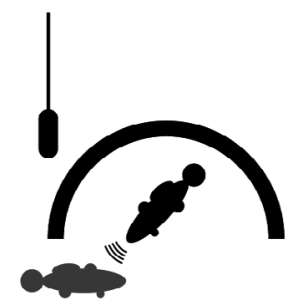

6. Prespawning

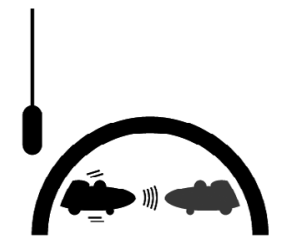

Figure 4 Behaviours associated with the sound production during reproductive interactions in Perccottus glenii. Descriptions: 1 . Leading: a courtship behaviour where the male completely leaves the nest, approaches the female and then rapidly returns to the reproductive site; 2 . Chase: male vigorously chases the female from the nest over a short $(>5 \mathrm{~cm})$ or long $(<5 \mathrm{~cm})$ distances while constantly biting her and producing sounds; 3 . Nest display: male is completely inside the nest while the female swims around and away from the entrance, i.e. there is no visual contact; 4. Frontal display: male is orientated toward the female from the nest entrance (there is visual contact), and the female is positioned less than five centimetres from the nest opening, but not inside; 5. Upside-down: male turns upside down in the nest so that its genital papilla comes in contact with the nest ceiling; 6. Pre-spawning: while the female is completely inside the nest, the male undulates the body and waves the pectoral fins with erected dorsal fins. Resident males are black and intruder females grey. Nest and hydrophone size not to scale.

the female was outside the nest or within the cavity. Acoustically, thumps were short duration $(<200 \mathrm{~ms})$ and low-frequency $(<500 \mathrm{~Hz})$ sounds, and exhibited an irregular waveform structure. Similar to sand gobies (Lindström \& Lugli, 2000; Amorim \& Neves, 2007; Malavasi et al., 2009),

Table 2 Sound parameters of recorded tonal sounds during reproductive interactions in three Perccottus glenii males

\begin{tabular}{llll}
\hline Sound parameters & Mean & SD & Range \\
\hline Tonal sounds & & & \\
$\quad$ Sound rate (sounds min $^{-1}$ ) & 6.4 & 1.2 & 4.7 to 7.7 \\
Duration (ms) & 89.7 & 16.8 & 70.4 to 119.5 \\
Number of cycles & 9.7 & 1.4 & 8.3 to 12.3 \\
Cycle repetition rate $(\mathrm{Hz})$ & 111.1 & 10.4 & 91.7 to 123.7 \\
Frequency modulation $(\mathrm{Hz})$ & 2.4 & 15.0 & -25.0 to 20.4 \\
Peak frequency $(\mathrm{Hz})$ & 117.1 & 4.5 & 112.3 to 124 \\
\hline
\end{tabular}

sounds of $P$. glenii were organized in long trains (sound bursts) composed from 2 to 12 thump sounds, whose mean acoustic parameters were similar to those of individually produced thumps. This study provides the first record of thump production outside the Gobionellidae, highlighting the complexity of acoustic signals within gobioids.

We also recorded tonal-like sounds, which were only previously observed in a small proportion of European gobiids from the Gobius lineage and Periophthalmodon septemradiatus (Ladich \& Kratochvil, 1989; Lugli et al., 1996, 1997; Malavasi et al., 2008; Sebastianutto et al., 2008; Polgar et al., 2011; Agorreta et al., 2013; Horvatić et al., 2015). In the case of $P$. glenii, tonal sounds on the spectrogram were almost flat non-modulated calls of short duration $(<100 \mathrm{~ms})$ with one important frequency peak $(\sim 120 \mathrm{~Hz})$ corresponding to the cycle repetition rate, indicating its sinusoidal quality. Perccottus glenii tonal calls show many common features with 
(a)

Thump sounds (bursts)

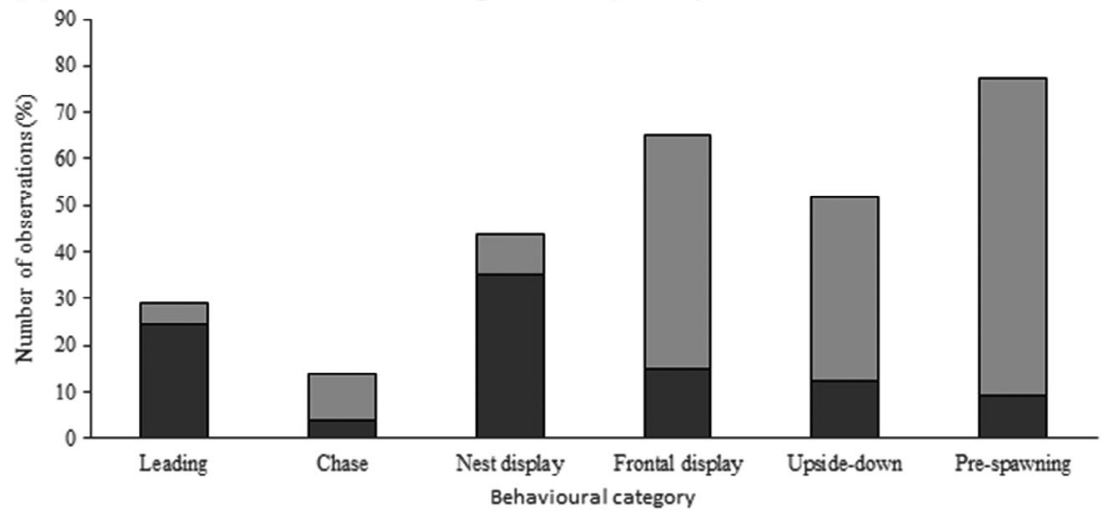

(b)

Tonal sounds

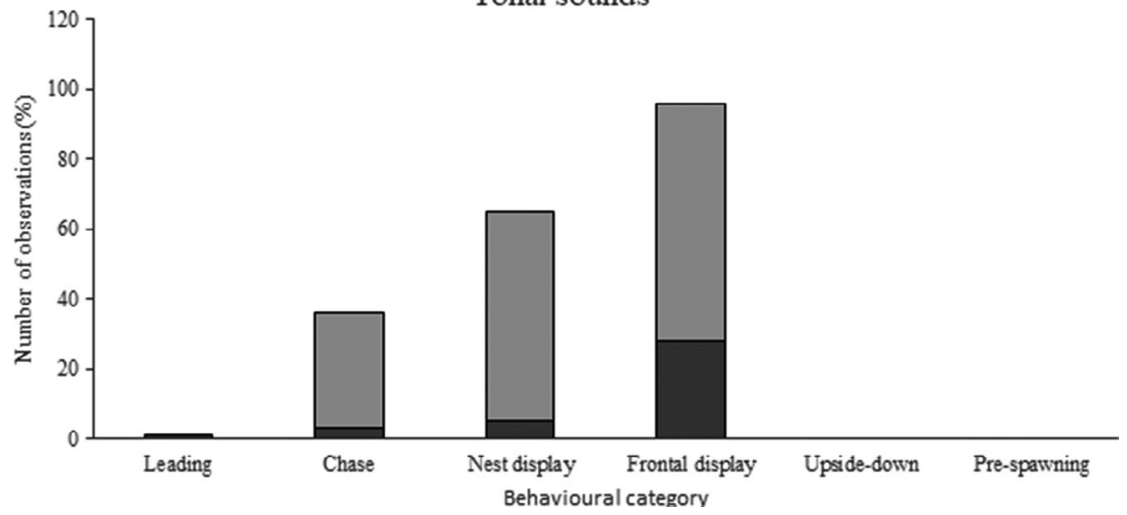

Figure 5 Percent of documented courtship behavioural acts (dark grey; total number of recorded acts; for thumps $(n=267)$ and tonal $(n=37)$ sounds) and the percentage of acts accompanied with the production of a) thump or b) tonal sounds (light grey) during courtship behaviour of Perccottus glenii males.

previously documented short tonal sounds described in certain gobiids, that is Neogobius fluviatilis and Padogobius nigricans (Lugli et al., 1996; Horvatić et al., 2015), highlighting the spectro-temporal acoustic complexity (short, non-modulated vs. long, frequency-modulated vocalizations) within gobioids, even in the case of tonal sounds. In P. glenii, short tonal sounds were frequent during the courtship phase, that is, when females were inspecting the male territory. Though the small sample size hinders us from drawing deeper conclusions, the occurrence of tonal sounds during the initial phase of the reproductive interactions (i.e. courtship) has been well documented in previous investigations of territorial nest-holding gobies (Ladich \& Kratochvil, 1989; Lugli et al., 1996; Horvatić et al., 2015). Our results emphasize the complex situation about reproductive sequence-specific sound types in gobies. We propose that, in the case of $P$. glenii, tonal sounds could serve for female attraction (i.e. when the female is outside the nest), while thump sounds are utilized in pre-spawning interactions, once the female has entered the nest hollow.

In this study, a relationship was found between water temperature and acoustic parameters, in both sound types. Sound characteristics are expected to change with temperature since it influences muscle contraction properties (Feher, Waybright
\& Fine, 1998), and in our case, thumps tended to have a higher number of cycles, cycle repetition rate and peak frequency in relation to higher temperatures within the burst. Tonal sounds were more frequency modulated and produced with a higher emission rate with increasing temperature. Although preliminary, our findings are consistent with the hypothesis about temperature-dependent sound-producing muscles in fishes (Bennett, 1985; Feher et al., 1998; Rome \& Lindstedt, 1998). However, detailed study is needed in order to understand how temperature variation affects acoustic features in P. glenii.

Male Padanian goby Padogobius bonelli produce tonal-like calls separately from drumming sounds, or combine them to form complex sounds (Lugli et al., 1995, 1997). Though the drumming and tonal components of complex sound never overlap, these components differ slightly in their acoustic parameters compared to the mean values of isolated sounds (shorter and with a lower number of pulses). Therefore, it was suggested that a single sonic mechanism could be responsible for sound production in P. bonelli (Lugli et al., 1995). Variation rates of the same muscles could generate either discrete pulses (drums) or rapidly repeated pulses yielding tone-like sounds. Our study demonstrates that $P$. glenii males were also 


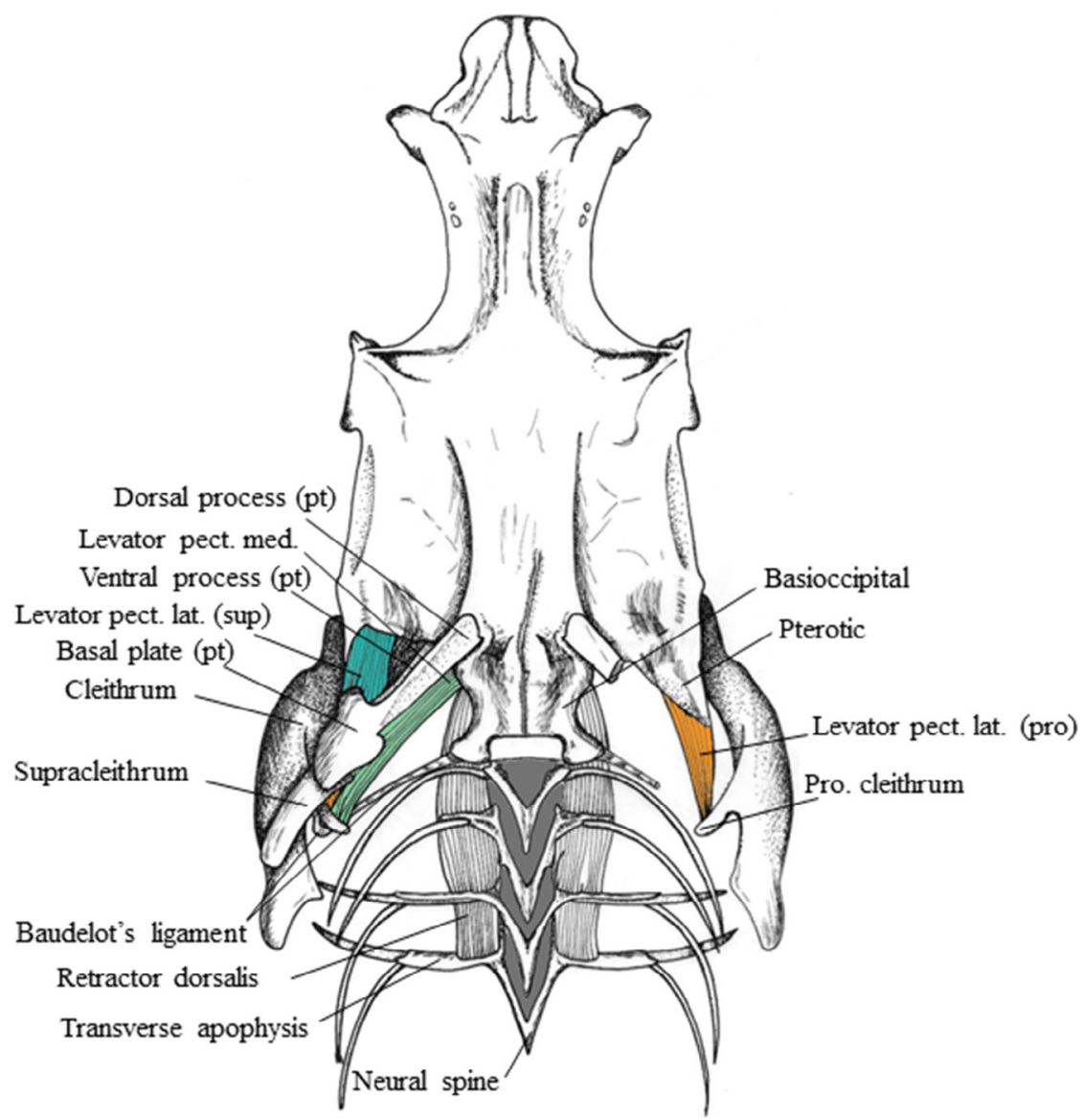

Figure 6 Dorsal view of the putative sound-producing mechanism in Perccottus glenii. On the right side, the posttemporal, levator pectoralis lateralis superficialis and levator pectoralis medialis muscles were removed to see the levator pectoralis lateralis profundus muscle.

able to produce two acoustically different sound types. However, the question remains as to how $P$. glenii thumps and tonal sounds are produced. No clear differences were observed in the cranio-pectoral movements associated with thump or tonal sound production. Further, we did not observe nodding behaviour or forward girdle displacement, as previously suggested for some cottids and gobies (Colleye et al., 2013; Zeyl et al., 2016). Therefore, it is possible that the basal odontobutid $P$. glenii possesses a single mechanism that is responsible for the production of both sound types. Detailed high-speed recordings and multidisciplinary research (muscle histology and electromyography) are needed to fully explain the sound emission process in $P$. glenii.

Fine et al. (2001) demonstrated that muscle contraction rate dictates the fundamental frequency of calls of the male oyster toadfish (Opsanus tau), with values overlapping peak sound amplitude. In our study, the comparison of oscillograms and power spectra between thump and tonal sounds provides interesting information. Dominant frequencies in both thump and tonal sounds mostly overlapped but thumps showed additional spectral components at frequencies above $200 \mathrm{~Hz}$ (Figs 1c and 3c). These additional components in thumps reflect the less regular sinusoidal shape of the oscillogram
(Fig. 1b). Contrary to this, the oscillogram shape of tonal sounds is more constant, providing less additional spectral components (Fig. 3c). In this case, tonal sounds could correspond to fully completed thumps. In other words, thumps and tonal sound could be produced by the same sound-producing mechanism involving the levator pectoralis contractions, though these contractions provide more regular cycles in tonal sounds.

According to Malavasi et al. (2008), interspecific comparison of acoustic signals across eleven Mediterranean gobies suggested that the pulsatile sound could represent an ancestral state within the gobies. In respect to this hypothesis, the present results broaden the evolutionary scenario regarding acoustic communication among the gobioids. We suggest that pulsatile (thump-like) and short tonal-like sounds could constitute the fundamental acoustic unit within the gobioids, since they are clearly documented in basal odontobutids (present study and Takemura, 1984). Although speculative, it is possible that these 'stem' sounds could have evolved in terms of temporal complexity (i.e. temporal spacing of pulse repetition) and frequency variation (modulation), presenting a diversity of long, frequency-modulated tonal and pulsatile/drumming signals reported currently for gobiids and gobionellids. By 
producing these fundamental units and additionally combining them, some gobiids (i.e. P. bonelli and Gobius cruentatus) have the ability to emit complex calls possessing both tonal and drumming components within the same burst.

\section{Conclusions}

This study supports the hypothesis that sound production and acoustic communication evolved early within the gobioid lineage. Thumps and short tonal-like sounds reported for the odontobutid $P$. glenii could be considered a synapomorphic trait for gobioid fishes. However, additional experimental study is required to determine whether sounds are produced in other basal gobioid families (mainly Eleotridae and Butidae) and to be able to compare them with other taxa. In addition, we propose that muscles originating on the skull and attaching to the pectoral girdle have an important role in the sound emission of $P$. glenii and therefore present a putative mechanism involved in their acoustic communication. In summary, this study expands the knowledge about gobioid vocal behaviour and underlines the importance of acoustic communication within this group of fish.

\section{Acknowledgements}

The authors are grateful to A. Špelić, D. Hamer and K. Horvat for their kind and useful assistance during the laboratory audiovideo recordings. We thank S. Sviben for initial paper revision and L. Zanella for proofreading the paper. In addition, we thank M. Vučković for figure preparation regarding behavioural acts. Lastly, authors are thankful to Michael L. Fine and an anonymous reviewer whose comments significantly improved the initial version of the paper. This research was funded by Ministry of Education, Science and Technological Development, Serbia (projects TR37009 and IO173045) and Ministry of Environment and Energy, Croatia (project 7055462).

\section{Conflict of interest}

None.

\section{References}

Adriaens, D., Decleyre, D. \& Verraes, W. (1993). Morphology of the pectoral girdle in Pomatoschistus lozanoi De Buen, 1923 (Gobiidae), in relation to pectoral fin adduction. Belg. J. Zool. 123, 137-157.

Agorreta, A., San Mauro, D., Schliewen, U., Van Tassell, J.L., Kovačić, M., Zardoya, R. \& Rüber, L. (2013). Molecular phylogenetics of Gobioidei and phylogenetic placement of European gobies. Mol. Phylogenet. Evol. 69, 619-633.

Akamatsu, T., Okumura, T., Novarini, N. \& Yan, H.Y. (2002). Empirical refinements applicable to the recording of fish sounds in small tanks. J. Acoust. Soc. Am. 112, 3073-3082.

Amorim, M.C.P. \& Neves, A.S.M. (2007). Acoustic signalling during courtship in the painted goby, Pomatoschistus pictus. J. Mar. Biol. Assoc. U.K. 87, 1017-1023.
Amorim, M.C.P. \& Neves, A.S.M. (2008). Male painted goby (Pomatoschistus pictus) vocalise to defend territories.

Behaviour 145, 1065-1083.

Bennett, A.F. (1985). Temperature and muscle. J. Exp. Biol. 115, 333-344.

Blom, E.L., Mück, I., Heubel, K. \& Svensson, O. (2016). Acoustic and visual courtship traits in two sympatric marine Gobiidae species - Pomatoschistus microps and Pomatoschistus minutus. Environ. Biol. Fishes 99, 999-1007.

Colleye, O., Ovidio, M., Salmon, A. \& Parmentier, E. (2013). Contribution to the study of acoustic communication in two Belgian river bullheads (Cottus rhenanus and C. perifretum) with further insight into the sound-producing mechanism. Front. Zool. 10, 71.

Feher, J.J., Waybright, T.D. \& Fine, M.L. (1998). Comparison of sarcoplasmic reticulum capabilities in toadfish (Opsanus tau) sonic muscle and rat fast twitch muscle. J. Muscle Res. 19, 661-674.

Fine, M.L., Malloy, K.L., King, C., Mitchell, S.L. \& Cameron, T.M. (2001). Movement and sound generation by the toadfish swimbladder. J. Comp. Physiol. A Sens. Neural. Behav. Physiol. 187, 371-379.

Freyhof, J. (2011). Diversity and distribution of freshwater gobies from the Mediterranean, the Black and Caspian seas. In The biology of gobies: 279-288. Patzner, R.A., Van Tassell, J.L., Kovačić, M. \& Kapoor, B.G. (Eds). Enfield: Science Publishers.

Horvatić, S., Cavraro, F., Zanella, D. and Malavasi, S. 2015.Sound production in the Ponto-Caspian goby Neogobius fluviatilis and acoustic affinities within the Gobius lineage: implications for phylogeny. Biol. J. Linn. Soc. 117, 564-573.

Kottelat, M. \& Freyhof, J. (2007). Handbook of European freshwater fishes. Kottelat, Comol, Switzerland andBerlin, Germany: Freyhof.

Ladich, F. \& Fine, M.L. (2006). Sound-generating mechanisms in fishes: a unique diversity in vertebrates. In Communication in fishes: 3-43. Ladich, F., Collin, S.P., Moller, P. \& Kapoor, B.G. (Eds). Enfield: Science Publishers.

Ladich, F. \& Kratochvil, H. (1989). Sound production by the marmoreal goby Proterorhinus marmoratus (Pallas) (Gobiidae, Teleostei). Zool. Jahrb. 93, 501-504.

Lindström, K. \& Lugli, M. (2000). A quantitative analysis of the courtship acoustic behaviour and sound patterning in male sand goby, Pomatoschistus minutus. Environ. Biol. Fish. 58, 411-424.

Lugli, M., Pavan, G., Torricelli, P. \& Bobbio, L. (1995). Spawning vocalizations in male freshwater gobiids (Pisces, Gobiidae). Environ. Biol. Fish. 43, 219-231.

Lugli, M., Torricelli, P., Pavan, G. \& Miller, P.J. (1996). Breeding sounds of male Padogobius nigricans with suggestions for further evolutionary study of vocal behaviour in gobioid fishes. J. Fish Biol. 49, 648-657.

Lugli, M., Torricelli, P., Pavan, G. \& Mainardi, D. (1997). Sound production during courtship and spawning among freshwater gobiids (Pisces, Gobiidae). Mar. Freshw. Behav. Physiol. 29, 109-126. 
Malavasi, S., Collatuzzo, S. \& Torricelli, P. (2008). Interspecific variation of acoustic signals in Mediterranean gobies (Perciformes, Gobiidae): comparative analysis and evolutionary outlook. Biol. J. Linn. Soc. 93, 763-778.

Malavasi, S., Valerio, C. \& Torricelli, P. (2009). Courtship sounds and associated behaviours in the Canestrini's goby Pomatoschistus canestrinii. J. Fish Biol. 75, 1883-1887.

Malavasi, S., Gkenas, C., Leonardos, I., Torricelli, P. \& McLennan, D.A. (2012). The phylogeny of a reduced 'sand goby' group based on behavioural and life history characters. Zool. J. Linn. Soc. 165, 916-924.

Miller, P.J. (1986). Gobiidae. In Fishes of the North-Eastern Atlantic and the Mediterranean: 1019-1085. Whitehead, P.J.P., Bauchot, M.L., Hureau, J.-C., Nielsen, J. \& Tortonese, E. (Eds). Paris: UNESCO.

Miller, P.J. (2003). Gobiidae I. In The freshwater fishes of Europe: 157-398. Miller, P.J. (Ed). Wiesbaden: Aula-Verlag. Myrberg, A.A. \& Lugli, M. (2006). Reproductive behavior and acoustical interactions. In Communication in fishes: 149-176. Ladich, F., Collin, S.P., Moller, P. \& Kapoor, B.G. (Eds). Enfield: Science Publishers.

Parmentier, E. \& Fine, M.L. (2016). Fish sound production: insight. In Vertebrate sound production and acoustic communication: 19-49. Suthers, R., Tecumseh, F., Popper, A.N. \& Fay, R.R. (Eds). New York: Springer.

Parmentier, E., Kéver, L., Boyle, K., Corbisier, Y., Sawelew, L. \& Malavasi, S. (2013). Sound production mechanism in Gobius paganellus (Gobiidae). J. Exp. Biol. 216, 3189-3199.

Parmentier, E., Petrinisec, M., Fonseca, P.J. \& Amorim, M.C.P. (2017a). Sound-production mechanism in Pomatoschistus pictus. J. Exp. Biol. 220, 4374-4376.
Parmentier, E., Diogo, R. \& Fine, M.L. (2017b). Multiple exaptations leading to fish sound production. Fish Fish. 18, 958-966.

Polgar, G., Malavasi, S., Cipolato, G., Georgalas, V., Clack, J.A. \& Torricelli, P. (2011). Acoustic communication at the water's edge: evolutionary insights from a mudskipper. PLOS ONE 6, e21434.

Rome, L.C. \& Lindstedt, S.L. (1998). The quest for speed: muscles built for high-frequency contractions. News Physiol. Sci. 13, 261-268.

Sebastianutto, L., Picciulin, M., Costantini, M., Rocca, M. \& Ferrero, E. (2008). Four types of sounds from one winner: vocalizations during territorial behaviour in the red-mouthed goby Gobius cruentatus (Pisces, Gobiidae). Acta Ethol. 11, 115-121.

Takemura, A. (1984). Acoustical behaviour of the freshwater goby Odontobutis obscura. Bull. Jpn. Soc. Sci. Fish. 50, 561564.

Thacker, C.E. (2009). Phylogeny of Gobioidei and placement within Acantomorpha with a new classification and investigation of diversification and character evolution. Copeia 2009, 93-104.

Winterbottom, R. (1974). A descriptive synonymy of the striated muscles of the Teleostei. Proc. Acad. Nat. Sci. Philad. 125, 225-317.

Zeyl, J.N., Malavasi, S., Holt, D.E., Noel, P., Lugli, M. \& Johnston, C.E. (2016). Convergent aspects of acoustic communication in darters, sculpins and gobies. In In fish hearing and bioacoustics: an anthology in honor of Arthur N. Popper and Richard R. Fay: 93-120. Sisneros, A.J. (Ed.). Switzerland: Springer. 